\title{
VESTÍGIOS DA TRADIÇÃO JUDAICA: BORGES E OUTROS RABINOS
}

Lyslei Nascimento*

RESUMO:

Este trabalho propõe-se a refletir sobre a obra de Jorge Luis Borges em sua relação com a tradição judaica. A inscrição de vestígios dessa tradição nos textos borgianos aponta para uma prática e uma poética que, ao utilizar estratégias de preservação da memória, delineiam um espaço narrativo $e$ performático em que a tradição cultural e literária encena identidades, discursos, poderes. Pensar a cultura latinoamericana como herdeira desse legado judaico revela-se como uma possibilidade de resistência e de sobrevivência do saber narrativo na contemporaneidade.

PALAVRAS-CHAVE: literatura, arquivo, memória, tradição, judaísmo.

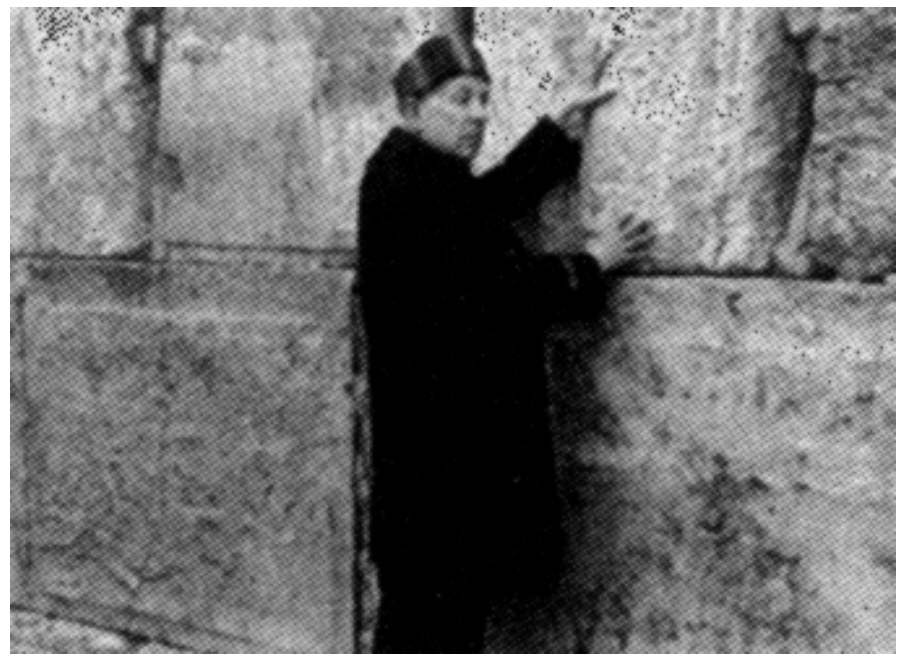

Data do final da década de 60 uma fotografia de Jorge Luis Borges junto ao Muro das Lamentações em Israel. Publicada em 1999 pela revista Proa $^{1}$, a fotografia, em preto e branco, sem data ou crédito, não é nítida. Vê-se, no entanto, o escritor diante da parede do que foi outrora a muralha que Herodes construiu em 20 a.C. ao |* Doutora em Letras: Estudos Literários (Área de concentração: Literatura Comparada), 2001. 


\section{EM TESE}

Belo Horizonte, v. 6, p. I-253, ago. 2003

redor do segundo Templo. Suas mãos tateiam como se lesse, em braile, o monumento. 0 muro, ruína da muralha, testemunhou séculos de história. Diante dele, Borges parece um homem pequeno e frágil.

A fotografia de Borges exibe as enormes pedras da construção que, justapostas, deixam ver os pequenos espaços que existem entre elas. Nas gretas e nos vãos que se formam, os fiéis inserem pequenos pedaços de papel com pedidos, orações, promessas. A ruína é lugar de culto e de adoração. Os judeus ortodoxos, com seus trajes e chapéus negros, movimentam o corpo e movem seus lábios em oração. 0 Templo, que sobrevive metonimicamente nessa parede, é a casa do Messias, a promessa da reconstrução de um terceiro Templo e do corpo judaico que foi disperso nas diásporas e exílios. Borges tateia, como quem lê, essa parede magnífica.

Sabe-se que o escritor esteve em Israel, a convite do governo israelense, por dez dias, em 1969, quando se encontrou com David Ben Gurion e Gershom Scholem. Em 1981, recebeu o mais importante reconhecimento literário concedido em Israel, o Prêmio Jerusalém. Borges visitou as praias do Mar Morto e lavou suas mãos no Mar da Galiléia. 0 encontro de tradições e o interesse específico pela tradição judaica, no entanto, não datam daí. A Bíblia e os ensinamentos religiosos, protestantes e católicos, além da literatura ocidental representada pela língua inglesa, através de Shakespeare, salientam as múltiplas forças que atravessaram o escritor argentino, tanto na América quanto na Europa, desde os anos de sua formação.

Edna Aizenberg afirma que Borges, ao nascer em uma cidade como a Buenos Aires de 1899, neto de ingleses e argentinos, possui, com essa mescla, uma condição privilegiada para um pensamento mais aberto e plural. Do legado britânico - do lado paterno da família - composto de protestantes, judeus, livres pensadores e metafísicos (AIZENBERG, 1999: 40), e do legado hispano-materno, que exalta um passado militar que valoriza a ortodoxia acima do intelecto, Borges subtrai, nessa dicotomia de traços contrários, suas ficções, construídas a partir do que Ricardo Piglia chamou de fábula biográfica. A construção textual borgiana se daria, por essa estratégia, a partir da confluência da ficção com relatos autobiográficos (PIGLIA, 1979: 3-6). Em meio à grande biblioteca inglesa do pai - de onde Borges disse nunca haver saído - e histórias de militares criollos surgiu a heterodoxia e o renomado cosmopolitismo do escritor. 
A familiaridade com os temas judaicos amplia-se com a chegada dos imigrantes europeus que aportaram na Argentina, trazendo um interessante contraponto à cidade de Buenos Aires e à vida do escritor. De um lado, no círculo do poder, estariam os ricos que se refugiavam na exclusividade do Jockey Clube. Representados politicamente pelo general Uriburu, uma espécie de Mussolini dos pampas, tinham como ideal artístico a glorificação nostálgica da vida rural. Do outro lado, estaria a Argentina do não-poder, os não tão ricos e os pobres, os estrangeiros, os trabalhadores, os anarquistas políticos e os intelectuais, cujas ações e escritos não ostentavam a permissão dos círculos oficiais. Para Jorge Guillermo Borges, fora da esfera do poder, todos esses são identificados como judeus, em oposição aos católicos privilegiados (AIZENBERG, 1999: 40).

Tal qual o pai, Borges vê o judaísmo como uma antítese do ultranacionalismo, da intolerância religiosa e da xenofobia que imperavam na Argentina. 0 pensamento dual e, por assim dizer, liberal e tolerante em relação às diferenças seria, para Aizenberg, o princípio da identificação de Borges com o judaísmo. Um judaísmo que se faz tolerante, principalmente devido a sua condição de religião e cultura exilada na América. Para Borges,

Aprender a pensar de duas maneiras diferentes, cada uma associada a uma tradição cultural, ou melhor, a um sistema de pensamento (ou descrença), foi muito benéfico para o futuro escritor. Isso o ensinou a apreciar outras culturas e a valorizar o diferente e o heterodoxo; tudo isso contribuiu para formar uma visão positiva do judaísmo (AIZENBERG, 1999: 42).

A dualidade lingüística - inglês/espanhol - também serviu de acesso aos textos da tradição judaica, principalmente à Bíblia, que é, para Borges, um livro hebreu, por excelência. 0 conhecimento da Escritura vem de sua avó inglesa, Fanny Haslam. Conta-se que ela podia dizer de cor, com as referências exatas, inúmeros versículos. No entanto, para o neto, a Bíblia seria, posteriormente, mais do que esse texto dogmático para se decorar e se aplicar às questões da vida cotidiana. Além de ser parte de sua herança britânica, a Bíblia seria, para o escritor, o ponto de partida, a base da ética ocidental e um dos textos fundamentais da literatura do Ocidente (ODED, 1977: 3).

Quando a família se muda para Genebra em busca de um tratamento para a cegueira hereditária do pai, Borges se torna amigo de vários judeus, entre eles, o 


\section{EM TESE}

Belo Horizonte, v. 6, p. I-253, ago. 2003

futuro advogado, escritor e poeta de origem polaco-judia, Maurice Abramowicz, para quem dedicou um texto-epitáfio, de rara e assombrosa beleza (BORGES, 2000: 526).

Obrigados a se exilarem na Europa porque eclode a I Grande Guerra, os Borges só retornam a Buenos Aires em 1921. Daí em diante, desde a publicação do primeiro livro, Fervor de Buenos Aires, em 1923, os encontros de Borges com a tradição judaica tornam-se cada vez mais freqüentes. A cada encontro, um vestígio da tradição judaica é entretecido a outras tradições do repertório do escritor. Mas o que poderia ser chamado de tradição para um escritor latino-americano?

Segundo Ricardo Piglia, para um escritor, a memória é a tradição. Uma memória impessoal, feita de citações em todas as línguas e em que fragmentos e tons de outras escrituras retornam como recordações pessoais (PIGLIA, 1990: 60-66). A tradição literária assim concebida seria, pois, como uma pré-história contemporânea, como resíduos de um passado cristalizado que se filtram no presente e se constituem enquanto memória pessoal (PIGLIA, 1990: 63).

De acordo com essa estratégia de construção ficcional, tal tradição se configuraria como um arquivo de bens culturais que, a partir de uma concepção de leitura e de escrita cada vez mais ampla e difusa, é acessado pelo escritor, que abre, com sua intervenção, possibilidades de confluências e combinações inusitadas.

A noção de arquivo enquanto um conjunto de bens culturais e práticas discursivas instaura enunciados como acontecimentos passíveis de serem reorganizados, traduzidos e revisados (FOUCAULT, 1987: 5-6). Essa concepção de arquivo se contrapõe à imagem da tradição entendida, metaforicamente, como um livro mítico em que as palavras intentam traduzir pensamentos constituídos e verdades estabelecidas ou inal teradas.

Como uma pré-história contemporânea, o resíduo do passado filtrado pelo presente é, portanto, uma estratégia quase ilimitada de apropriação e recriação ficcional. Na obra de Jorge Luis Borges, esse modo de elaborar a tradição cultural e literária delineia uma reflexão crítica sobre a construção de textos do presente, que se articulam com vestígios culturais do passado e, simultaneamente, uma forma de repensar a tradição canônica, não em sua unicidade imaginada, mas enquanto um repertório de múltiplas tradições que podem ser acessadas, adulteradas, reencenadas em outros contextos e trançadas com outras tradições. 
Longe de possuir uma pretensão arqueológica, o texto borgiano, quando se apropria de traços do passado que sobrevivem no texto do presente, rearranja essas tradições, ou esse legado, e a elas agrega novos sentidos que parecem configurar um traço da narrativa contemporânea. Rearticular esse passado significa, no tocante à narrativa borgiana, empreender uma retomada da tradição cultural, apropriar-se de arquivos e textos que nela se inscrevem, não como um paradigma a ser copiado, mas como uma reminiscência, como já anunciava Walter Benjamin, "tal como ela relampeja no momento de um perigo"(BENJAMIN, 1993: 224).

0 perigo para a tradição e a memória estaria, pois, no esquecimento total, na amnésia absoluta. No conto "Funes, el memorioso" (BORGES, 1989: 485-490), Borges, ao construir uma trama ancorada num personagem que, paralítico, depois de um acidente, é capaz de recordar absolutamente tudo que leu, viu e sentiu, evidencia o caráter monstruoso da memória que não permite o esquecimento. 0 escritor pensa, a partir dessa contingência, num registro cristalizado e inerte, num arquivo morto. Sendo assim, Irineu Funes acaba por morrer, ironicamente, de congestão pulmonar. A lição de Borges parece clara. Aquele que não se deixa construir entre o duplo movimento de lembrar e de esquecer está fadado ao que mais teme, à morte. Engendrar a tradição cultural a partir dessa concepção de memória dispersa, sujeita aos desvãos da desmemoria, seria, pois, um traço constitutivo da literatura borgiana e, talvez também, da literatura e da arte contemporâneas.

A apropriação e a recontextualização de vestígios da tradição cultural, fazendo transmigrar letra e voz de um contexto para outro, partilhando memórias e textos, recorrendo ao arquivo da tradição cultural e efetuando sua leitura, sua tradução, assumindo perdas, esquecimentos e adulterações, seria um procedimento de Borges que o afastaria dos embates com a tradição empreendidos por Kafka, por exemplo, mas o aproximaria dos procedimentos rabínicos de leitura e escritura, de interpretação e de comentário, a partir da tradição religiosa.

Esse pressuposto, no entanto, não desconsidera a diferença de estatuto dos textos religiosos em relação aos ficcionais. 0 que parece determinar a aproximação de Borges a esses escritos que proliferam ao redor da tradição religiosa judaica é o contínuo reescrever da tradição sem, contudo, pretender-se a sua eliminação. 


\section{EM TESE}

Belo Horizonte, v. 6, p. I-253, ago. 2003

Ao descontextualizar restos de uma tradição e inseri-los em outro espaço e em outro tempo, o escritor argentino embaralha acervos, obtém cópias infiéis, distribui moedas falsas, enfim, rearranja e potencializa o sentido que recolhe e reinsere em outro contexto. Quando reorganiza a ordem do arquivo legado pela tradição cultural e literária e recorta dele fragmentos de que necessita para engendrar um outro texto, Borges desterritorializaria essa tradição tal como ela é concebida, reinventando-a em outro espaço-tempo (LÉVY, 1998: 3).

A obra de Jorge Luis Borges se apresenta como paradigmática desse jogo em que a tradição cultural e literária ocidental se constitui como um arquivo de tradições diversas, que podem ser acessadas e reconfiguradas. Acercar-se desse arquivo e considerar o que se apresenta como um indecifrável labirinto de textos parece ter sua origem numa concepção de literatura e de arte em que signos, metáforas, temas e mesmo projetos de escrita podem se manter e se constituir dentro e fora do universo da tradição considerada canônica.

Para Borges, e também para outros escritores e artistas que se apropriam de vestígios de uma tradição cultural, seja ela canônica ou menor, como a judaica, por exemplo, abrem-se horizontes múltiplos que redimensionam o sentido e o espaço para uma possível reflexão sobre a construção da escrita e da arte, que têm como ponto de partida a memória própria e a alheia. Pensar como uma imagem, deslocada de um certo arquivo, passa a ter, num outro contexto, outra configuração sem, no entanto, perder completamente seu sentido, estabelece novas conexões e caminhos a se percorrer que reorganizam a ordem dentro do que se poderia chamar de tradição cultural.

0 modo de ação do escritor ou artista que relê e acessa um arquivo que o antecede implica, assim, um jogo de transmissões, de retomadas, de citações e de repetições. Constituído por vestígios de cultura, de onde se retiram fragmentos dispersos da memória, esse arquivo pode atingir desfechos não previstos. Nesse sentido, o que se acessa não é mais a tradição imaginada como um todo coeso, mas o rastro, o recorte e a inserção que nela pode ser efetuada (FOUCAULT, 1989: 5-6).

Tal como a imagem de Borges no Muro das Lamentações, onde as preces são inseridas nas fendas, a escrita e a arte contemporâneas se inscreveriam na tradição cultural por frestas e espaços que se evidenciam pela relação, já anunciada desde 
Benjamin, entre lembrar e esquecer. Essa relação entre a tradição cultural e os procedimentos borgianos de construção de uma tradição literária ou ficcional pode ser notada no ensaio "El escritor argentino y la tradición", no qual Borges ressalta a possibilidade de um ponto de vista privilegiado do escritor argentino, e por extensão, sul-americano, em relação ao manejo de outras tradições:

Creo que los argentinos, los sudamericanos en general, estamos en una situación análoga; podemos manejar todos los temas europeos, manejarlos sin supersticiones, con una irreverencia que puede tener, y ya tiene, consecuencias afortunadas. (BORGES, 1989: 273)

A situação semelhante àquela que Borges se refere é a dos judeus e a dos irlandeses. Ao refletir sobre a tradição literária argentina, o escritor ilustra seu pensamento a partir da dispersão desses povos na cultura ocidental. Aos judeus, afirma, sempre será mais fácil que a um ocidental não-judeu inovar a cultura ocidental, porque eles atuam dentro da cultura e, ao mesmo tempo, não se sentem atados a ela por uma devoção especial (BORGES, 1989: 274).

A proposta literária borgiana, assim, parece pensar o passado, com seu léxico, procedimentos e temas, não como um ponto de partida, um bem intocável a ser preservado, mas como um texto a ser reinventado, um arquivo aberto. Nesse sentido, o passado não é reverenciado como material inerte, mas concebido como um tecido de citações, um trabalho de bricolagem em que uma tensão entre o escritor e a tradição redefine a memória e a leitura, como tradução e transformação (MIRANDA, 1998: 22). Borges não efetua, dessa forma, a ruptura com a tradição tal qual empreendida pelo modernismo, ou tal como pode ser notada em Kafka, enquanto contestação aos valores nela vigentes. Não passa pelas suas estratégias de construção literária abolir o "estrato arqueológico" que estaria sedimentado na cultura. Sua obra se inscreve, pois, na produção contemporânea ao efetuar um outro olhar sobre a tradição cultural, já não considerada como sagrada e imperecível, mas a articularia, pela linguagem, a outros discursos. Não é o caso, portanto, de evocar os monumentos do passado e de revitalizar de forma nostálgica rastros no aí feitos, nem tampouco, destruí-1os, mas criar uma estratégia, sem melancolia, de reorganizar e redefinir vestígios possíveis de tradições próprias e alheia para constituir, assim, outras tradições, outras narrativas. 


\section{EM TESE}

Belo Horizonte, v. 6, p. I-253, ago. 2003

ABSTRACT :

The presence of the Jewish tradition in contemporary art and literature is discussed in the works of Jorge Luis Borges. The inscription of traces of this tradition in Borges' texts points to the practice of a poetics that outlines a narrative and performing space in which cultural and literary traditions enact identities, discourses and powers, through memory preserving strategies. This approach to Latin American culture as an heir to the Jewish heritage revealed itself as a possibility of resistance and survival of current narrative knowledge.

KEY WORDS: literature, archive, memory, tradition, judaism.

REFERÊNCIAS BIBLIOGRÁFICAS

AIZENBERG, Edna. Por que se interesa Borges por el judaísmo. In: Sefárdica. n. 6. Buenos Aires: CIDICSEF, 1999.

BENJAMIN, Walter. Obras escolhidas: magia e técnica, arte e política. Trad. Sérgio Paulo Rouanet. São Paulo: Brasiliense, 1993.

BORGES, Jorge Luis. Obras Completas I. Buenos Aires: Emecé, 1989.

- Obras Completas II, Buenos Aires: Emecé, 1989

. Obras completas III. Trad. Josely Vianna Baptista. São Paulo: Globo, 2000.

FOUCAULT, Michel. A arqueologia do saber. Trad. Luiz Felipe Baeta Neves. Rio de Janeiro: ForenseUniversitária, 1987.

LÉVY, Pierre. A reencarnação do saber. Folha de São Paulo, São Paulo, 22, fevereiro, 1998. Mais!

MIRANDA, Wander Melo. A memória de Borges. In: Borges em dez textos. Belo Horizonte: Curso de Pós-Graduação em Letras da FALE / UFMG; Rio de Janeiro: Sette Letras, 1998.

ODED, Sverdlik. Borges habla de Israel y los judíos. Nuevo mundo israelita. n. 190, mar. 1977.

PIGLIA, Ricardo. Ideología y ficción en Borges. Punto de vista, 2, n. 5, mar. 1979.

- Memoria y tradición. In: CONGRESSO ABRALIC, 2, 1990, Belo Horizonte. Anais... Belo Horizonte: SEGRAC. 1990 . 